\title{
A novel mutation in the OAR domain of PITX3 associated with congenital posterior subcapsular cataract
}

\author{
Qi Fan' ${ }^{1,2,3,4,5}$, Dan $\mathrm{Li}^{1,2,3,4,5}$, Lei Cai ${ }^{1,2,3,4,5}$, Xiaodi Qiu ${ }^{1,2,3,4,5}$, Zhennan Zhao ${ }^{1,2,3,4,5}$, Jihong Wu ${ }^{1,2,3,4,5}$,
} Jin Yang ${ }^{1,2,3,4,5^{*}+}$ and Yi Lu ${ }^{1,2,3,4,5^{*}+}$ (D)

\begin{abstract}
Background: Congenital cataract is the most common cause of blindness among children worldwide. The aim of this study was to identify causative mutations in a Chinese family with isolated autosomal dominant posterior subcapsular cataract.

Methods: The proband and her parents underwent full ophthalmological examinations. DNA was extracted from the participants' peripheral venous blood. The mutation was identified via panel-based next-generation sequencing (NGS) and was validated via Sanger sequencing.

Results: Posterior subcapsular lenticular opacity was observed in both of the proband's eyes. The novel deletion mutation c.797_814del, p.Ser266_Ala271del in the PITX3 gene was identified in the proband and her father. This mutation is located within the otp/aristaless/rax (OAR) domain at the $\mathrm{COOH}$-terminus of the protein, which functions in DNA binding and transactivation. This mutation would result in a deletion of 6 amino acid residues at the $C$ terminal of the protein.

Conclusions: The mutation c.797_814del, p.Ser266_Ala271del is a novel mutation in the conserved DNA-binding OAR domain of PITX3 that causes congenital cataract.
\end{abstract}

Keywords: Congenital cataract, PITX3, The OAR domain

\section{Background}

Congenital cataract is defined as lens opacity that occurs at birth or during the first decade of life. With an estimated incidence of 1 to 7.2 cases per 10,000 live births [1-3], congenital cataract is responsible for 10 to $38 \%$ of pediatric blindness worldwide [4]. In approximately $70 \%$ of cases [5], congenital cataract presents as an isolated eye abnormality. Congenital cataract can also occur in association with other ocular and/or systemic abnormalities, such as anterior segment mesenchymal dysgenesis (ASMD), Peters anomaly, Lowe syndrome, and Nance-Horan syndrome.

Between 8.3 and $25 \%$ of congenital cataracts are hereditary [6]. To date, genetic studies have identified over

\footnotetext{
*Correspondence: jin_er76@hotmail.com; luyieent@126.com

${ }^{\dagger}$ Jin Yang and Yi Lu contributed equally to this work.

${ }^{1}$ Department of Ophthalmology and the Eye Institute, Eye and Ear, Nose, and

Throat Hospital, Fudan University, 83 Fenyang Rd, Shanghai, People's

Republic of China

Full list of author information is available at the end of the article
}

100 causative genes for congenital cataract, including many with minor additional features (e.g., $A B C A 3$ [7], CRYAA [8]). Among these genes, over 30 causative genes have been implicated in association with isolated inherited congenital cataract. These genes may be arbitrarily divided into four major groups [9]: crystallin genes, membrane protein genes, cytoskeletal protein genes, and DNA- or RNA-binding protein genes.

In recent years, the diagnostic use of gene panel next-generation sequencing (NGS) techniques have become commonplace for individuals with hereditary diseases [10]. It has enabled the analysis of a greater number of genes, with the advantage of being fast and inexpensive. We customized a gene capture panel to identify genetic defects in ophthalmic diseases. It was designed to encompass the exons and untranslated (UTR) regions of 790 genes related to eye disease, which included retinal disease genes (FZD4, NDP, LRP5,

(c) The Author(s). 2019 Open Access This article is distributed under the terms of the Creative Commons Attribution 4.0 International License (http://creativecommons.org/licenses/by/4.0/), which permits unrestricted use, distribution, and reproduction in any medium, provided you give appropriate credit to the original author(s) and the source, provide a link to the Creative Commons license, and indicate if changes were made. The Creative Commons Public Domain Dedication waiver (http://creativecommons.org/publicdomain/zero/1.0/) applies to the data made available in this article, unless otherwise stated. 
TIMP3,TLR4, ABCA4, RP1, and RP2, among others), neuro-ophthalmic disease genes (e.g., $C R X, C R B 1, O P A 1$, $O P A 3)$, corneal disease genes (e.g., CHST6, TCF4, ZEB1), glaucoma genes (e.g., $A S B 10, O P T N, M Y O C$ ) and others. In particular, this gene panel contains all of the reported causative genes for congenital cataract, including the CRYAA, CRYAB and PITX3 gene.

In this paper, we present two members of a four-generation family with isolated autosomal dominant posterior subcapsular cataract. The aim of this study was to identify causative mutations in the proband and her family that resulted in congenital cataract by using a gene panel.

\section{Methods}

All procedures were performed in accordance with the Declaration of Helsinki and were approved by the Ethics Committee of the Eye \& ENT Hospital of Fudan University. Written informed consent was obtained from all individuals who participated in this study and from responsible adults on behalf of minors.

\section{Patients}

Three members of a four-generation Chinese family were enrolled in this study, including the proband (IV:3) and her parents (the father III:5 and the mother III:6). Two of them were affected with autosomal dominant congenital cataract (the proband IV:3 and her father III:5). They received a comprehensive ophthalmological examination at the Department of Ophthalmology of the Eye \& ENT Hospital of Fudan University. This examination included tests of uncorrected visual acuity (UCVA) and best corrected visual acuity (BCVA), Goldmann applanation tonometry, and detailed slit-lamp and fundus examinations. Others family members were not enrolled, but their affected status was obtained from the medical records of the local hospital from previous ophthalmological examinations.

\section{Panel-based next-generation sequencing}

Five milliliters of peripheral venous blood from the three participants was collected in tubes containing EDTA. DNA was isolated from the whole-blood samples using a Gentra Puregene Blood Kit (Qiagen, Valencia, CA) in accordance with the manufacturer's protocol and was stored at $-20^{\circ} \mathrm{C}$ until used for sequencing. No DNA from the other family members was available for targeted mutation testing.

All three DNA samples were subjected to analysis using panel-based NGS that involved a targeted gene region capture protocol to identify genetic defects. This protocol and the capture probes were custom designed and produced by Beijing Genomics Institute (BGI, Shenzhen, China), as previously reported. [11] The output sequence data were aligned to the reference human genome UCSC hg38 using Burrows-Wheeler Aligner, version 0.7.10. The variants were filtered to eliminate benign variants with MAF (minor allele frequency) > $0.1 \%$ in the 1000 Genomes dataset, and the dbSNP, EXAC, Tumor Heart Freq_Hom, ESP6500, and internal databases. All 790 genes were considered equally. Finally, variant prioritization was performed by combining the total depth, quality score, MAF, potential deleterious effect and the existence of mutation reports in common databases, such as The Human Gene Mutation Database (HGMD), The Retinal Information Network (RetNet), ClinVar, and Online Mendelian Inheritance in Man (OMIM). Variants were classified as benign, likely benign, pathogenic, likely pathogenic or novel variants of uncertain clinical significance according to the American College of Medical Genetics and Genomics (ACMG) guidelines [12].

\section{PITX3 gene mutation validation}

Sanger sequencing was used to confirm the detected variant. First, polymerase chain reaction (PCR) was performed on the sample using the primers F:5'-GTGTCCTGC CCTTATGCCTC-3' and R:5'-GGAGGCTGTGAATC GTTGC-3' for PITX3. The PCR program included activation at $94{ }^{\circ} \mathrm{C}$ for $3 \mathrm{~min}$; followed by 30 cycles of $94{ }^{\circ} \mathrm{C}$ for $20 \mathrm{~s}, 60^{\circ} \mathrm{C}$ for $20 \mathrm{~s}$, and $72^{\circ} \mathrm{C}$ for $40 \mathrm{~s}$; and a final extension at $72{ }^{\circ} \mathrm{C}$ for $3 \mathrm{~min}$. The PCR products were subjected to direct DNA sequencing by Generay Biotechnology Co., Ltd.

\section{Results}

\section{Clinical features}

The pedigree of the family enrolled in this study is shown in Fig. 1 (Only the proband and her parents were enrolled in the study). There are four generations that include 11 affected individuals, five unaffected individuals and 8 spouses. The proband (IV:3) was born with bilateral congenital cataract. Her BCVA was 0.4 (logMar unit) in her right eye and 1.0 (logMar unit) in her left eye when she was first referred to our hospital at the age of 10. Posterior subcapsular lenticular opacity was observed in both eyes, with heavier opacity in the left eye than in the right eye (Fig. 2 a, b, c and d). Cataract extraction with posterior capsulotomy, anterior vitrectomy and intraocular lens (IOL) implantation was performed. One year after surgery, both eyes reached a BCVA of 0.1 (logMar unit), with a clear optical axis. The proband's father (III:5) had also suffered from congenital cataract since childhood. He underwent cataract extraction with IOL implantation at the age of 18 , resulting in a bilateral BCVA of 0.7 (logMar unit). He presented with pseudophakia in both eyes and mild IOL dislocation in the right eye (Fig. $2 \mathrm{E}$ and F). The patients had no ocular or systemic abnormalities other than cataract. 


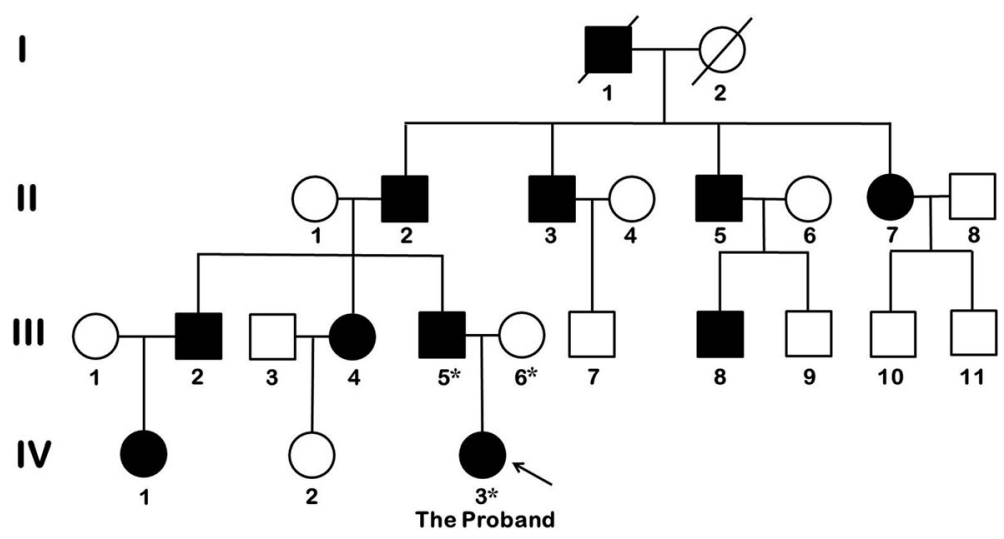

Fig. 1 Pedigree of the family enrolled in this study. Squares and circles represent males and females, respectively. Open and solid symbols indicate unaffected and affected individuals, respectively. Astericks indicate enrolled individuals. The proband, IV:3, is indicated with an arrow

\section{PITX3 mutation analysis}

After the data acquisition and analysis, a total of 14,076 raw variants were found in the 790 genes, and 211 variants (Additional file 1: Table S1) met the filtering criteria. Based on valuable information in published literatures, we included the genes that were of autosomal dominant genetic inheritance pattern and congenital

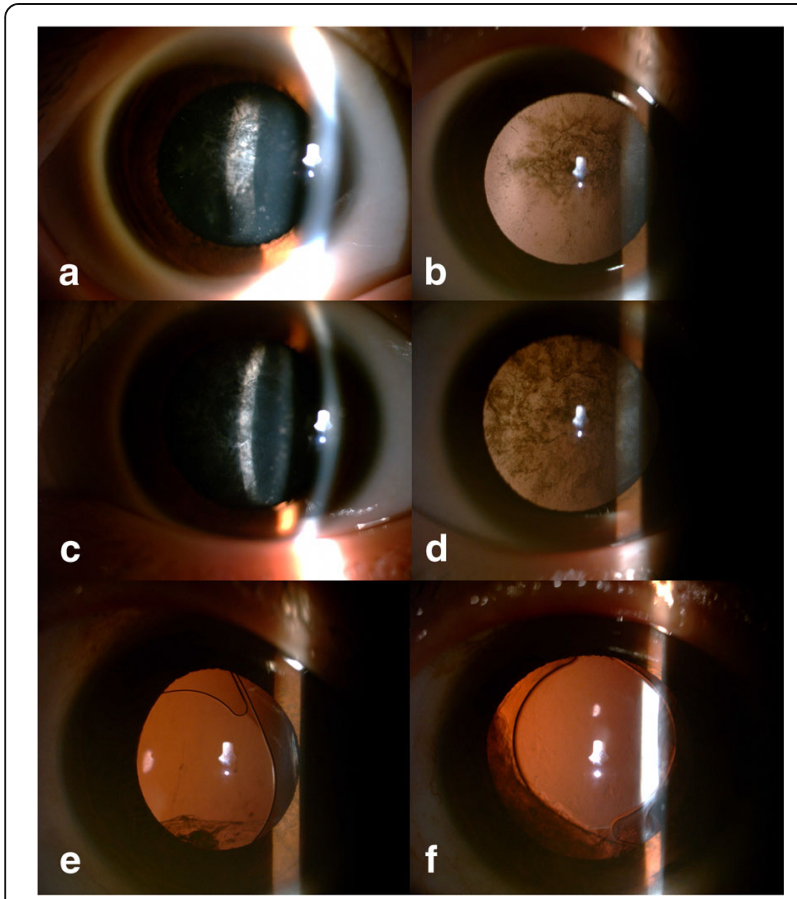

Fig. 2 Clinical features of participants. Direct illumination and retroillumination slit-lamp photographs of the proband's right eye (a and $\mathbf{b}$ ) and left eye (c and $\mathbf{d}$ ). Posterior subcapsular lenticular opacity was observed in both eyes, and more heavily in the left eye than in the right eye. Retroillumination slit-lamp photographs of the proband's father's (III:5) right (e) and left (f) eye. He underwent cataract extraction with intraocular lens implantation, and pseudophakia in both eyes and mild IOL dislocation in the right eye are apparent cataract. Finally, one deletion mutation (c.797_814del, p.Ser266_Ala271del) in PITX3 was identified as a potentially pathogenic mutation. This mutation was identified in IV:3 and III:5 (Fig. 3) and was validated by Sanger sequencing. The PITX3 deletion mutation had not been recorded in the public mutation GnomAD database (http://gnomad.broadinstitute.org/). The mutation is classified as an uncertain clinical significance mutation according to the ACMG guidelines (criteria PM2, PM4, and PP1). It is located within the otp/aristaless/rax (OAR) domain at the C-terminus of the protein (Fig. 4), which functions in DNA binding mediated by protein-protein interactions. This mutation would result in a deletion of 6 amino acid residues at the C-terminus of the protein (266-271, from a total of 302).

\section{Discussion}

There have been many commercial gene panels used in clinical practice [13]. Gene panels are very helpful in diagnosing hereditary diseases with genetic and phenotypic heterogeneity, including hereditary eye diseases. They have the capacity to identify a large number (from tens to hundreds) of genes with potential clinical utility. They can provide better sensitivity for point mutations, deletion/insertion mutations within $20 \mathrm{bp}$ and homozygous deletions in exons. However, a limitation of gene panel assays is that they are not capable of large copy number variation and genomic structural variation. Additionally, they not able to explore possible causative mutations outside the gene list contained in the panel.

In this study, we detected the c.797_814del, p.Ser266_Ala271del mutation, a novel deletion variant of PITX3 that is associated with congenital posterior subcapsular cataract, by using a genetic testing panel. PITX3 is a DNA-binding protein gene, which are often associated with more complex phenotypes such as ASMD. 
a The Proband

IV:3

\section{b The Proband's Father} III:5

\section{The Proband's Mother} III: 6
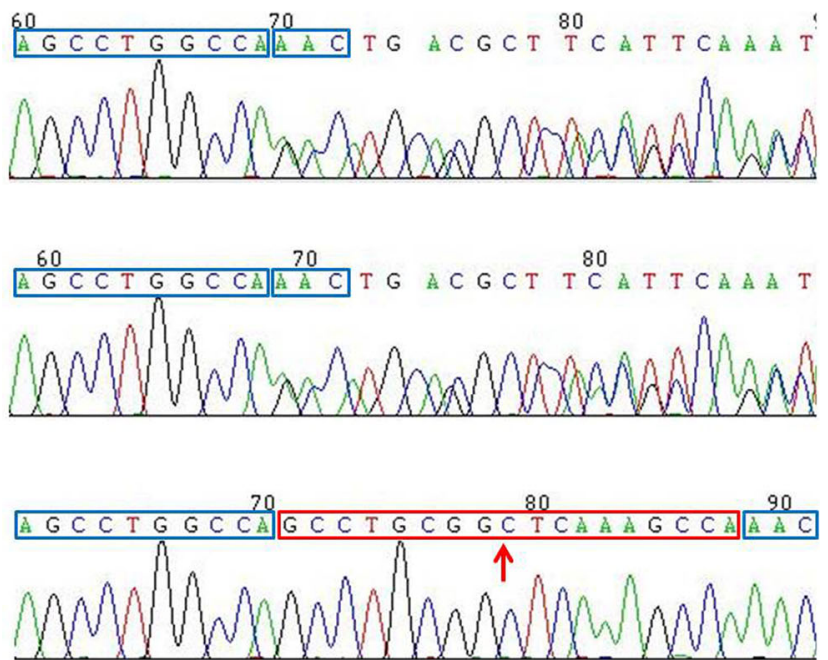

Fig. 3 Sequencing analysis of the PITX3 mutation. Sequence analysis of PITX3 showing an 18 bp deletion in the affected individuals IV:3 (a) and III:5 (b). The wild-type sequence is shown in $\mathbf{c}$, and the nucleotides deleted in $\mathbf{a}$ and $\mathbf{b}$ are indicated using a red box and a red arrow

However, the family described in this paper does not appear to have any additional features.

PITX3, which belongs to the PITX/RIEG family of homeobox genes, contains characteristic and strongly conserved homeobox and C-terminal OAR domains that function in DNA binding and transactivation. It plays a critical role in normal lens development during vertebrate eye formation. Mutations in PITX3 are linked to developmental abnormalities of the anterior eye, particularly the lens. Knockdown of Pitx3 in mouse induced small eyes without lenses [14]. In addition, mutations in PITX3 are responsible for various ocular defects [15], including congenital cataract, ASMD, Peters anomaly, and microphthalmia.

PITX3 mutations play a role in the pathogenesis of congenital cataract, including both dominant and recessive types of cataract with or without other ocular abnormalities. Previously, 9 unique PITX3 mutations [16, 17] (c.38G > A, p.Ser13Asn; c.542delC, p.Pro181LeufsX127; c.573delC, p.Ser192AlafsX117; c.582delC, p.Ile194MetfSX115; c.608delC, p.Ala203GlyfsX105;

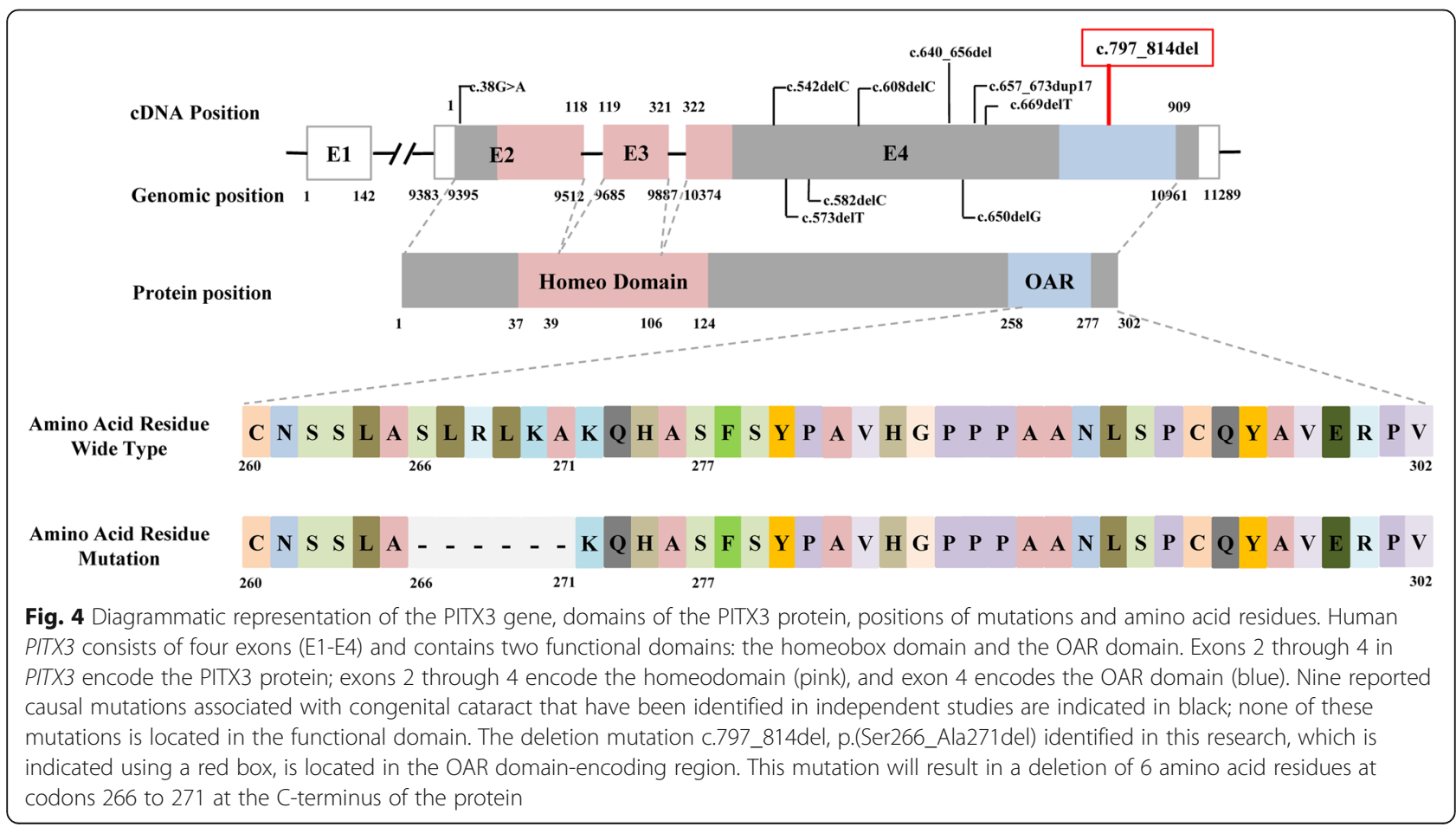


c.640_656del, p.Ala214ArgfsX42; c.650delG, p.Gly217AlafsX91; c.669delC, p.Leu225TrpfsX84; and c. 640_656dup17, p.Gly220ProfsX95) that cause congenital cataract have been reported. Except c.38G > A, p.Ser13Asn mutation, other mutations are in exon 4 and are frameshift mutations. The c.640_656del, p.Ala214ArgfsX42 mutation is recessive, while the rest are dominant. The $17 \mathrm{bp}$ duplication mutation c. 640_656dup17, p.Gly220ProfsX95 has been identified as the most common of these mutations in humans since it was first described by Semina et al. [18]. However, it is interesting that no mutation had previously been identified in either the homeodomain- or the OAR domain-encoding region of PITX3. The mutation identified in this paper is a mutation located within the OAR domain-encoding region.

The OAR domain is a strongly conserved functional domain. Previous studies have revealed that it is involved in specific protein-protein interactions and plays multiple regulatory roles. It functions as an intramolecular switch of transactivation activity in the Cart1 homeoprotein by inhibiting DNA binding [19]. It also serves as a repressor of transcription in PITX3; loss of the OAR domain leads to an enhancement of PITX3 transcription and translation [20]. Simultaneously, it is essential for ensuring the normal expression of downstream genes of PITX3, such as Mip and Foxe3, via protein-protein interactions [20]. Although the functions of the OAR domain are not yet well understood, it has been proven that disruption of the OAR domain of the PITX3 protein is associated with alterations in DNA-binding profiles and/or transactivation activities [21].

The deletion mutation in this study was an in-frame deletion mutation. It resulted in a deletion of 6 amino acid residues at the $\mathrm{C}$-terminus that altered the OAR domain. Interestingly, the majority of previously reported-PITX3 mutations were out-of-frame deletions that lead to the disruption of the OAR domain, while this in-frame deletion would not be expected to do so. Perhaps its DNA-binding profile and/or transactivation activities may have been altered. However, whether the OAR domain folding or the DNA-binding profile and/or transactivation activities were altered was not clear. Further functional analyses and DNA-protein binding assays are required to confirm the molecular mechanism.

\section{Conclusions}

This investigation reports a novel mutation in PITX3, which adds to our knowledge of the mutations in PITX3 that cause inherited cataract. The majority of reported mutations in PITX3 result in a loss of the OAR domain, as they cause frameshifts prior to the OAR domain, while the mutation identified in this paper was located within the OAR domain-encoding region. However, it is a limitation of this study that more distant family members could not be recruited and tested. The exact pathogenicity of the mutation is still unclear; therefore, further experiments are needed to investigate the mechanisms of mutation in the PITX3 pathway during lens development.

\section{Additional file}

Additional file 1: Table S1. The full filtering variants of the genetic testing panel. (XLSX 62 kb)

\section{Abbreviations}

BCVA: Best corrected visual acuity; IOL: Intraocular lens; NGS: Next-generation sequencing; OAR domains: Otp/aristaless/rax domains; PCR: Polymerase chain reaction; PITX3: Paired-like homeodomain 3 transcription factor;

UCVA: Uncorrected visual acuity; UTRs: Untranslated regions

\section{Acknowledgements}

The DNA samples used for the analyses described in this manuscript were isolated and stored at the EENT Biobank. We would like to thank all the participants and the staff for their valuable contribution to this research.

\section{Funding}

This work was supported by grants from the National Natural Science Foundation of China for the Eye and ENT Hospital of Fudan University (grants 81600718 and 81670835 ). The funding organization had no role in the design or conduct of this research.

\section{Availability of data and materials}

The datasets used and analyzed during the current study are available from the corresponding author on reasonable request.

\section{Authors' contributions}

QF drafted and revised the manuscrip. LC, XQ and ZZ acquired and analysed the data. DL and JHW analysed and interpretated the data. $Y L$ and JY designed the study protocol, revised the manuscript and conducted the study as a supervisor. All authors read and approved the final manuscript.

\section{Ethics approval and consent to participate}

All procedures were performed in accordance with the Declaration of Helsinki and were approved by the Ethics Committee of the Eye \& ENT Hospital of Fudan University. Written informed consent was obtained from all individuals who participated in this study and from responsible adults on behalf of minors.

\section{Consent for publication}

All the family members in this pedigree consented to the publication of their family relationship and clinical and genetic test results.

\section{Competing interests}

The authors declare that they have no competing interests.

\section{Publisher's Note}

Springer Nature remains neutral with regard to jurisdictional claims in published maps and institutional affiliations.

\section{Author details}

${ }^{1}$ Department of Ophthalmology and the Eye Institute, Eye and Ear, Nose, and Throat Hospital, Fudan University, 83 Fenyang Rd, Shanghai, People's Republic of China. ${ }^{2}$ The Key Laboratory of Myopia, Ministry of Health, 83 Fenyang Rd, Shanghai, People's Republic of China. ${ }^{3}$ Shanghai Key Laboratory of Visual Impairment and Restoration, 83 Fenyang Rd, Shanghai, People's Republic of China. ${ }^{4}$ Key National Health Committee Key Laboratory of Myopia, Fudan University, 83 Fenyang Rd, Shanghai, People's Republic of China. ${ }^{5}$ Laboratory of Myopia, Chinese Academy of Medical Sciences, 83 Fenyang Rd, Shanghai, People's Republic of China. 
Received: 9 August 2018 Accepted: 11 March 2019

Published online: 20 March 2019

\section{References}

1. Francis PJ, Berry V, Bhattacharya SS, Moore AT. The genetics of childhood cataract. J Med Genet. 2000;37:481-8.

2. Graw J. Congenital hereditary cataracts. Int J Dev Biol. 2004:48:1031-44.

3. Verdin H, Sorokina EA, Meire F, Casteels I, de Ravel T, Semina EV, De Baere E. Novel and recurrent PITX3mutations in Belgian families with autosomal dominant congenital cataract and anterior segment dysgenesis have similar phenotypic and functional characteristics. Orphanet J Rare Dis. 2014;9:26

4. Foster A, Gilber C, Pechi J. Epidemiology of cataract in childhood, a global perpective. J Cataract Refract Surg. 1997;23(Suppl 1):601-4.

5. Haargaard B, Wohlfahrt J, Fledelius HC, Rosenberg T, Melbye M. A nationwide Danish study of 1027 cases of congenital/infantile cataracts: etiological and clinical classifications. Ophthalmology. 2004; 111:2292-8.

6. Yi J, Yun J, Li ZK, Xu CT, Pan BR. Epidemiology and molecular genetics of congenital cataracts. Int J Ophthalmol. 2011;4:422-32.

7. Chen P, Dai Y, Wu X, Wang Y, Sun S, Xiao J, Zhang Q, Guan L, Zhao X, Hao $X, W u R$, Xie L. Mutations in the ABCA3 gene are associated with cataractmicrocornea syndrome. Invest Ophthalmol Vis Sci. 2014;55:8031-43.

8. Song Z, Si N, Xiao W. A novel mutation in the CRYAA gene associated with congenital cataract and microphthalmia in a Chinese family. BMC Med Genet 2018 Oct 19:19:190.

9. Shiels A, Hejtmancik JF. Molecular genetics of cataract. Prog Mol Biol Transl Sci. 2015:134:203-18

10. Ellingford JM, Horn B, Campbell C, Arno G, Barton S, Tate C, Bhaskar S, Sergouniotis PI, Taylor RL, Carss KJ, Raymond LFL, Michaelides M, Ramsden SC, Webster AR, Black GCM. Assessment of the incorporation of CNV surveillance into gene panel next-generation sequencing testing for inherited retinal diseases. J Med Genet. 2018;55:114-21.

11. Huang $X Y$, Zhuang $H, W u$ JH, Li JK, Hu FY, Zheng $Y$, Tellier LCAM, Zhang SH, Gao FJ, Zhang JG, Xu GZ. Targeted next-generation sequencing analysis identifies novel mutations in families with severe familial exudative vitreoretinopathy. Mol Vis. 2017;23:605-13 eCollection 2017.

12. Richards S, Aziz N, Bale S, Bick D, Das S, Gastier-Foster J, Grody WW, Hegde M, Lyon E, Spector E, Voelkerding K, Rehm HL. ACMG laboratory quality assurance committee. Standards and guidelines for the interpretation of sequence variants: a joint consensus recommendation of the American College of Medical Genetics and Genomics and the Association for Molecular Pathology. Genet Med. 2015:17:405-24.

13. Buys SS, Sandbach JF, Gammon A, Patel G, Kidd J, Brown KL, Sharma L, Saam J, Lancaster J, Daly MB. A study of over 35,000 women with breast cancer tested with a 25-gene panel of hereditary cancer genes. Cancer. 2017;123:1721-30

14. Semina EV, Murray JC, Reiter R, Hrstka RF, Graw J. Deletion in the promoter region and altered expression of Pitx3 homeobox gene in aphakia mice. Hum Mol Genet. 2000:9:1575-85.

15. Sakazume S1, Sorokina E, Iwamoto Y, Semina EV. Functional analysis of human mutations in homeodomain transcription factor PITX3. BMC Mol Biol 2007;8:84

16. Zazo Seco C, Plaisancié J, Lupasco T, Michot C, Pechmeja J, Delanne J, Cottereau E, Ayuso C, Corton M, Calvas P, Ragge N, Chassaing N. Identification of PITX3 mutations in individuals with various ocular developmental defects. Ophthalmic Genet. 2018;39:314-20.

17. Anand D, Agrawal SA, Slavotinek A, Lachke SA. Mutation update of transcription factor genes FOXE3, HSF4, MAF, and PITX3 causing cataracts and other developmental ocular defects. Hum Mutat. 2018; 39:471-94.

18. Semina EV, Reiter RS, Murray JC. Isolation of a new homeobox gene belonging to the Pitx/Rieg family: expression during lens development and mapping to the aphakia region on mouse chromosome 19. Hum Mol Genet. 1997;6:2109-16.

19. Brouwer A, ten Berge D, Wiegerinck R, Meijlink F. The OAR/aristaless domain of the homeodomain protein Cart1 has an attenuating role in vivo. Mech Dev. 2003;120:241-52.
20. Wada K, Matsushima Y, Tada T, Hasegawa S, Obara Y, Yoshizawa Y, Takahashi G, Hiai H, Shimanuki M, Suzuki S, Saitou J, Yamamoto N, Ichikawa M, Watanabe K, Kikkawa Y. Expression of truncated PITX3 in the developing lens leads to microphthalmia and aphakia in mice. PLoS One. 2014:9: e111432.

21. Sakazume S, Sorokina E, Iwamoto Y, Semina EV. Functional analysis of human mutations in homeodomain transcription factor PITX3. BMC Mo Biol. 2007:8:84
Ready to submit your research? Choose BMC and benefit from:

- fast, convenient online submission

- thorough peer review by experienced researchers in your field

- rapid publication on acceptance

- support for research data, including large and complex data types

- gold Open Access which fosters wider collaboration and increased citations

- maximum visibility for your research: over $100 \mathrm{M}$ website views per year

At BMC, research is always in progress.

Learn more biomedcentral.com/submissions 